Arab J. Nucl. Sci. Appl., Vol. 53, 2, 78-86 (2020)

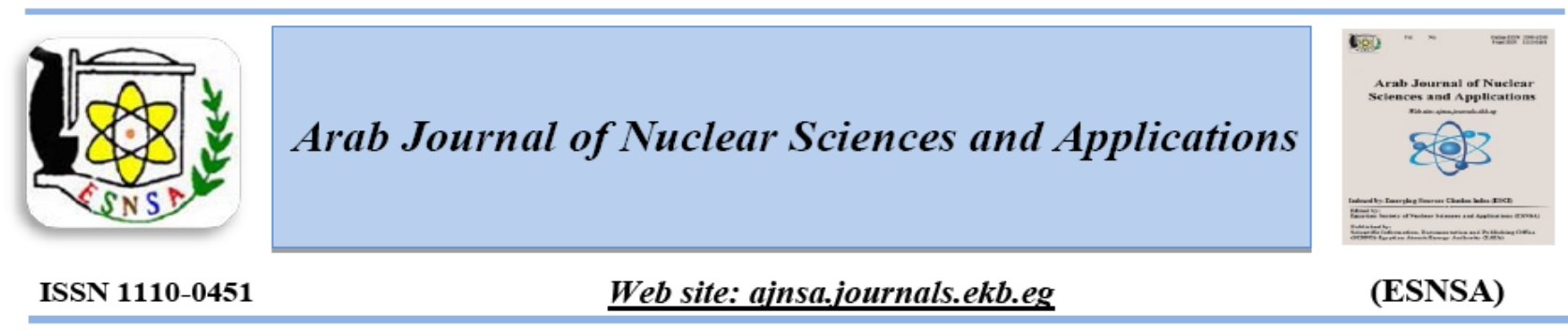

\title{
Linearized Mathematical Model for PWR Dynamics Simulation
}

Nehad A. Demerdash1, Mohamed A. El-Hameed2, Mahdy M. El-Arini2, Ezzat A. Eisawy1

(1) Egyptian Nuclear \& Radiological Regulatory Authority, Nasr City P.O. Box7551, Cairo, Egypt. (2) Electrical Power and Machines Department, Zagazig University, Zagazig 44519, Egypt

Received $28^{\text {th }}$ Oct. 2019 Accepted $17^{\text {th }}$ Nov. 2019
A linearized mathematical model for the pressurized water reactor (PWR) nuclear power plant dynamics simulation is presented based on conservation of energy and mass balance. The core and coolant system are treated as a lumped parameter. The delayed neutrons effect is considered. The model state variables are linearized in first order differential equations with steady state initial values. The reactor core dynamic response is investigated through transients represented in external reactivity insertion e.g. $(0.001 \Delta \mathrm{k} / \mathbf{k}), 10 \%$ step decrease in core flow rate and $10{ }^{\circ} \mathrm{F}$ step decrease in core inlet coolant temperature. The simulation results demonstrated the role of feedback reactivity form coolant temperature and Doppler Effect in stabilizing the core power and affecting the steady state values of core variables.

Keywords: Nuclear power plant / Pressurized water reactor / Reactor simulation / Feedback, reactor dynamics

\section{Introduction}

Nuclear energy is considered as one of the most important sources of a clean and cheap energy. Therefore, there is a need to investigate the safety and stability of nuclear power plants. Safety issues have two main aspects, stability of plant under physical and thermal transients and stability of plant following the power grid disturbances. This paper focuses on the reactor core stability subjected to input transients. As it is difficult to perform this study practically, the need arises to model the reactor core and simulate it to monitor the reactor reaction under the different transients. Reactor simulation modeling is handled previously in published papers. In [1] a pressurized water reactor model was proposed and implemented through a user-defined program in PSASP where, the dynamics of the reactor due to common step disturbances in reactivity and coolant temperature were simulated. The model simulation clarified the importance of feedbacks to reactor stability.The same reactor model for dynamic analysis [2] was implemented by Scilab where, the response of core variables to perturbations in reactivity, inlet coolant temperature and primary coolant flow rate were presented. The author assessed the results by PWR model developed in [3] depending on the positive reactivity perturbation and the differences were attributed to different design values and thermal hydraulic

Corresponding author: nehadali_2004@yahoo.com

DOI: 10.21608/ajnsa.2019.18780.1290

(c) Scientific Information, Documentation and Publishing Office (SIDPO)-EAEA 
conditions. Also, the same reactor model was introduced in many published papers as a part of the whole PWR nuclear power plant for the purpose of studying dynamic characteristics of PWR [4] or power system analysis as in [5-6]. In a recent work [7] the dynamics simulation approach by adopting reactor model to investigate the thermal dynamic processes is presented. This model was validated using results from published work in
[8]. In the present work, a reactor model suitable for the dynamic analysis is proposed, in which the feedback from coolant temperature and fuel temperature effects are considered to model the true characteristics of the reactor. The model is implemented and the reactor dynamics can be easily investigated through perturbations applied to control input parameter.

\section{Nomenclature}

$A_{f C} \quad$ Effective heat transfer surface area between

PSAP Power System Analysis Software Package the reactor fuel and primary coolant, $\left(\mathrm{ft}^{\wedge}\right)$.

$C_{i} \quad$ Precursor concentration for the $\mathrm{i}^{\text {th }}$ precursor group, $\mathrm{i}=1, \ldots ., 6$

$C_{P C} \quad$ Reactor coolant specific heat, (Btu/lb. $\left.{ }^{\circ} \mathrm{F}\right)$.

$C_{P f} \quad$ Reactor fuel specific heat, (Btu/lb. ${ }^{\circ} \mathrm{F}$ )

$F_{r} \quad$ Fraction of total power generated in fuel. $\quad \mathrm{T}_{\mathrm{UP}}$

$M_{f} \quad$ Mass of reactor fuel, (lb).

$M_{C} \quad$ Mass of reactor coolant,(lb)

$M_{L P} \quad$ Mass of coolant in lower plenum, (lb).

$M_{H L} \quad$ Mass of coolant in hot leg, (lb)

$P_{r} \quad$ Normalized core thermal power

$P \quad$ Reactor thermal power, (MWth).

$P_{0} \quad$ Initial reactor thermal power, (MWth).

$T_{f} \quad$ Average fuel temperature, $\left({ }^{\circ} \mathrm{F}\right)$

$T_{f 0} \quad$ Average initial fuel temperature, $\left({ }^{\circ} \mathrm{F}\right)$

$T_{C 1} \quad$ Primary coolant temperature at lump1,( $\left.{ }^{\circ} \mathrm{F}\right)$

$T_{C 2} \quad$ Primary coolant temperature at lump2, $\left({ }^{\circ} \mathrm{F}\right)$

$T_{C 0} \quad$ Primary coolant average temperature, $\left({ }^{\circ} \mathrm{F}\right)$

$T_{C L} \quad$ Primary coolant temperature in cold-leg, $\left({ }^{\circ} \mathrm{F}\right) \quad \lambda_{\mathrm{i}}$

$T_{P S G O}$ Temperature of primary coolant out from $\rho_{\text {ext }}$ steam generator, $\left({ }^{\circ} \mathrm{F}\right)$.

$T_{H L} \quad$ Primary coolant temperature in hot-leg, $\left({ }^{\circ} \mathrm{F}\right) \quad \rho_{0}$

Scilab A numerical computational high level software

$\mathrm{T}_{\mathrm{LP}} \quad$ Primary coolant temperature in reactor lower plenum, $\left({ }^{\circ} \mathrm{F}\right)$

UP Primary coolant temperature in reactor upper plenum. $\left({ }^{\circ} \mathrm{F}\right)$

$\mathrm{U}_{\mathrm{fC}} \quad$ Heat transfer coefficient from fuel to coolant

$\mathrm{W}_{\text {PRIM }}$ Primary coolant mass flow rate inside the core.

$\beta_{\mathrm{t}} \quad$ Total delayed neutron fraction, $\beta_{\mathrm{t}}=\sum_{1}^{6} \beta_{\mathrm{i}}$

$\beta_{\mathrm{i}} \quad$ Delayed neutron fraction for the six delayed-neutron groups, $\mathrm{i}=1, . ., 6$

$\Lambda \quad$ Neutron generation time, (s).

$\alpha_{\mathrm{f}} \quad$ Fuel temperature coefficient of reactivity, $(1 / \mathrm{oF})$

$\alpha_{c} \quad$ Coolant temperature coefficient of reactivity, $\left(1 /{ }^{\circ} \mathrm{F}\right)$

Delayed neutron group decay constant, $1 / \mathrm{s}$

External reactivity due to control rod movement

Initial value of core reactivity

\section{Plant Dynamic Model}

The plant dynamic model is structured in a way to include reactor neutron dynamic, reactor thermodynamic, plant components such as reactor plenums and piping. Plant state variables are represented by first order differential equations based on the conservation of mass and energy laws. Reactor neutron dynamic is modeled by using the point kinetic equation with six groups of delayed neutrons and the reactivity feedback from fuel and coolant temperatures are considered in total reactivity. It is assumed that the spatial distribution shape of the neutron flux density do not change during the transients [9-11].

Reactor Kinetics Model 


$$
\begin{gathered}
\frac{d P_{r}(t)}{d t}=\left(\frac{\rho(t)-\beta_{t}}{\Lambda}\right) * P_{r}(t)+\sum_{i=1}^{6} \lambda_{i} * \\
\text { Crit, } \quad P r=P P O \\
\frac{d C_{r i}(t)}{d t}=\frac{\beta_{i}}{\Lambda} P_{r}(t)-\lambda_{i} C_{r i}(t), \quad i=1: 6
\end{gathered}
$$

\section{B. Reactor Core thermal dynamic model}

The core heat transfer model utilizes mann's [10] approximation for fuel and coolant temperatures as shown in Figure (1). Two well stirred coolant nodes are used for each fuel node to obtain a good approximation to the heat transfer driving force between fuel and coolant.

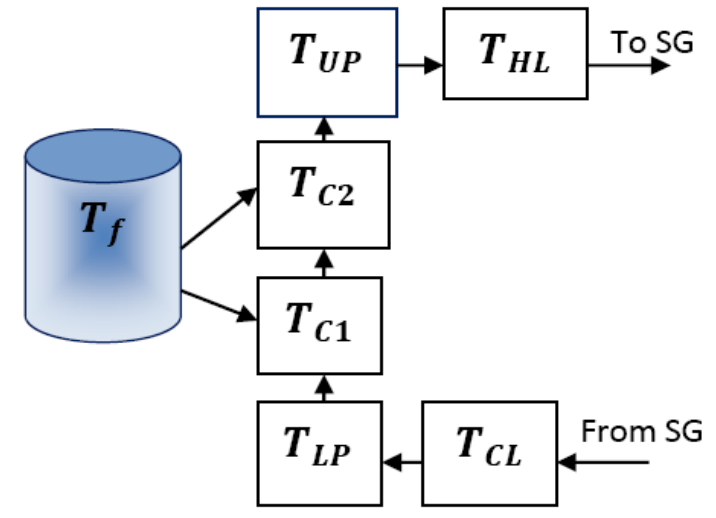

Figure (1): Schematic diagram of reactor thermal model lumps

$$
\begin{gathered}
\frac{d T_{f}}{d t}=\frac{F_{r} P_{0}}{M_{f} C_{P f}} P_{r}-\frac{U_{f C} A_{f C}}{M_{f} C_{P f}} T_{f}+\frac{U_{f C} A_{f C}}{2 M_{f} C_{P f}} T_{C 1} \\
+\frac{U_{f C} A_{f C}}{2 M_{f} C_{P f}} T_{C 2} \\
\frac{d T_{C 1}}{d t}=\frac{\left(1-F_{r}\right) P_{0}}{M_{C} C_{P C}} P_{r}+\frac{U_{f C} A_{f C}}{M_{C} C_{P C}}\left(T_{f}-T_{C 1}\right) \\
+\left(\frac{W_{P R I M}}{M_{C}}\right)\left(T_{L P}-T_{C 1}\right)
\end{gathered}
$$

$$
\begin{gathered}
\frac{d T_{C 2}}{d t}=\frac{\left(1-F_{r}\right) P_{0}}{M_{C} C_{P C}} P_{r}+\frac{U_{f C} A_{f C}}{M_{C} C_{P C}}\left(T_{f}-T_{C 1}\right) \\
+\left(\frac{W_{P R I M}}{M_{C}}\right)\left(T_{C 1}-T_{C 2}\right)
\end{gathered}
$$

\section{Core reactivity}

The total reactivity in the core is represented by the initial value of reactivity in core and external reactivity caused by a change in rod movement and reactivity feedback induced by change in fuel temperature (Doppler Effect), and by change in coolant temperature.

$$
\begin{gathered}
\rho(t)=\rho_{0+} \rho_{\text {ext }}+\alpha_{f} *\left(T_{f}-T_{f 0}\right)+\alpha_{c} \\
*\left(T_{C}-T_{C 0}\right)
\end{gathered}
$$

\section{Reactor Piping and Plenums}

In reactor plenums، Figure (1), complete mixing is assumed during normal transients. The energy conservation equation are applied on both plenums, this will result in two first order lag equations for the upper and lower plenum temperatures.

$$
\begin{aligned}
\frac{d T_{L P}}{d t} & =\frac{W_{P R I M}}{M_{L P}}\left(T_{C L}-T_{L P}\right) \\
\frac{d T_{U P}}{d t} & =\frac{W_{P R I M}}{M_{U P}}\left(T_{C 2}-T_{U P}\right) \\
\frac{d T_{C L}}{d t} & =\frac{W_{P R I M}}{M_{C L}}\left(T_{P S G O}-T_{C L}\right) \\
\frac{d T_{H L}}{d t} & =\frac{W_{P R I M}}{M_{H L}}\left(T_{U P}-T_{H L}\right)
\end{aligned}
$$

The above-mentioned equations are linearized with reference to the steady state initial values and presented in state space form as shown in equations (11)

$$
\dot{X_{\mathrm{R}}}=\mathrm{A}_{\mathrm{R}} * \mathrm{X}_{\mathrm{R}}+\mathrm{B}_{\mathrm{R}} * \mathrm{U}_{\mathrm{R}}
$$

Where, $\dot{X}_{R}$ : Reactor state variables vector, $A_{R}$ :Reactor coefficient matrix, $B_{R}$ : Coefficient of reactor input matrix, $\mathrm{U}_{\mathrm{R}}$ : Reactor input variables 
vector. Equation (11) can be detailed to represent PWR reactor state space model as follows:

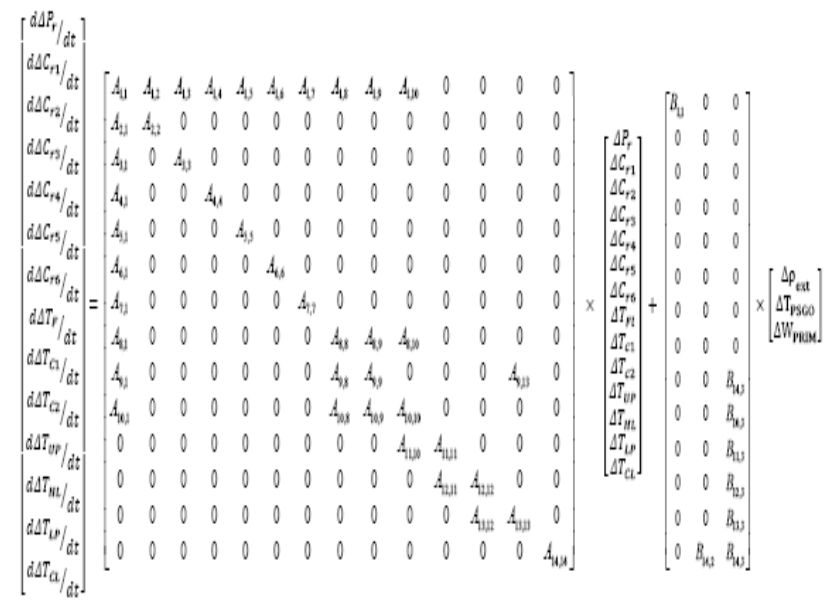

Elements of matrix $A$ and matrix $B$ are listed in details in appendix A.The block diagram for the reactor state space model is shown in (Figure 2).

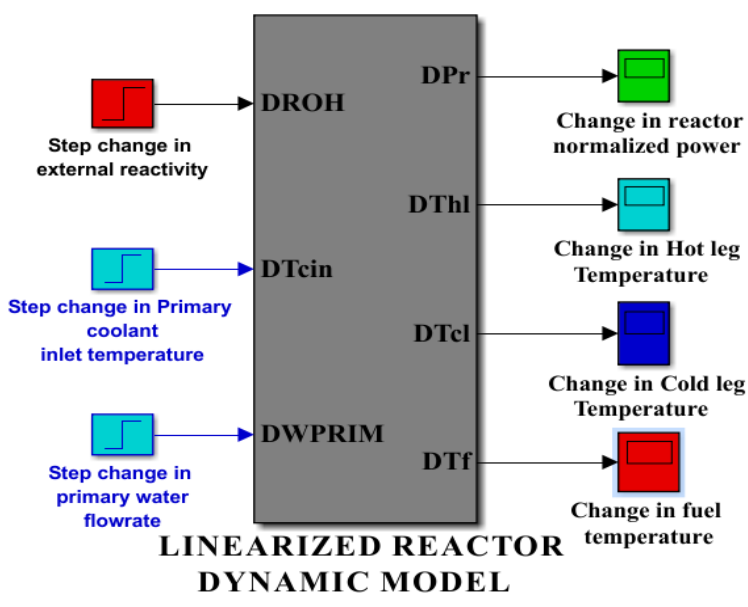

Figure (2): Block diagram of reactor state space model

\section{Simulation of reactor dynamics}

The reference plant for developed reactor model is a typical Westinghouse PWR system with thermal energy power $3436 \mathrm{MWth}$. The technical parameters required for construction of the reactor model are listed in table (1) and delayed neutron data are listed in table (2), [12-13].
Table (1): Reference PWR technical parameter.

\begin{tabular}{|l|c|}
\hline Parameter & Value \\
\hline $\begin{array}{l}\text { Nominal Power Output (MWth) thermal } \\
\text { power }\end{array}$ & 3436 \\
\hline Fraction of Total Power Generated in Fuel. & 0.974 \\
\hline Mass of Fuel (Ibm). & 222739 \\
\hline Total Coolant Mass Flow Rate (Ibm/hr) & $1.5 \times 10^{8}$ \\
\hline Effective Heat Transfer Area (ft ${ }^{2}$ ). & 59900 \\
\hline Specific Heat Capacity of Fuel (btu/Ibm- ${ }^{0}$ F). & 0.059 \\
\hline $\begin{array}{l}\text { Specific Heat Capacity of Moderator } \\
\text { (btu/Ibm - }{ }^{0} \text { F). }\end{array}$ & 1.39 \\
\hline $\begin{array}{l}\text { Average Overall Heat Transfer Coefficient } \\
\text { (btu/Ibm-ft }{ }^{2} \text { ). }\end{array}$ & 200 \\
\hline
\end{tabular}

Table (2): Six group delayed neutron data.

\begin{tabular}{|l|c|c|}
\hline Group & $\begin{array}{c}\text { Delay Neutron } \\
\text { Fraction }\end{array}$ & Decay Constant \\
\hline First & $\beta_{1}=0.000209$ & $\lambda_{1}=0.012500 \mathrm{~s}^{-1}$ \\
\hline Second & $\beta_{2}=0.001414$ & $\lambda_{2}=0.030800 \mathrm{~s}^{-1}$ \\
\hline Third & $\beta_{3}=0.001309$ & $\lambda_{3}=0.114000 \mathrm{~s}^{-1}$ \\
\hline Fourth & $\beta_{4}=0.002727$ & $\lambda_{4}=0.307000 \mathrm{~s}^{-1}$ \\
\hline Fifth & $\beta_{5}=0.000925$ & $\lambda_{5}=1.190000 \mathrm{~s}^{-1}$ \\
\hline Sixth & $\beta_{6}=0.006898$ & $\lambda_{6}=3.190000 \mathrm{~s}^{-1}$ \\
\hline
\end{tabular}

Three different cases of transient are simulated in this study to examine reactor dynamics:-

- Step reactivity increase

- Decrease in inlet core coolant Temperature

- Decrease in primary coolant flow rate

\section{RESULTS}

In the following a summary of the reactor core dynamic response results for the simulated transient cases are presented:-

\section{A. Reactor Response for Step Reactivity Increase}

A sudden reactivity increase can be due to a control rod withdrawal or a boron dilution or a suddenpump start up. Such event had been simulated by adding a $(0.001 \Delta \mathrm{k} / \mathrm{k}$ (i.e., $0.15 \$)$ as a step increase in the core reactivity, (Figure 3(d)). Accordingly, fission rate increases resulting in neutron flux increase, and correspondingly, reactor thermal power rises sharply 
to a value of about $15 \%$ from rated power. As the reactor power generation increases, the fuel temperature will increases to a value of $50{ }^{\circ} \mathrm{F}$ in 5 seconds, from the simulation time, this means that there is a delay between fuel temperature and power increase (Figure 3(b)).The increase in fuel temperature, leads to more heat generated in core which is transferred to the coolant, rising its temperature as shown in (Figure 3(b)).The temperatures of the two coolant modeled lumps, e.g. $\Delta \mathrm{Tc} 1 \& \Delta \mathrm{Tc} 2$, rises to a value of $1.44^{\circ} \mathrm{F}$, and $2.76^{\circ} \mathrm{F}$,

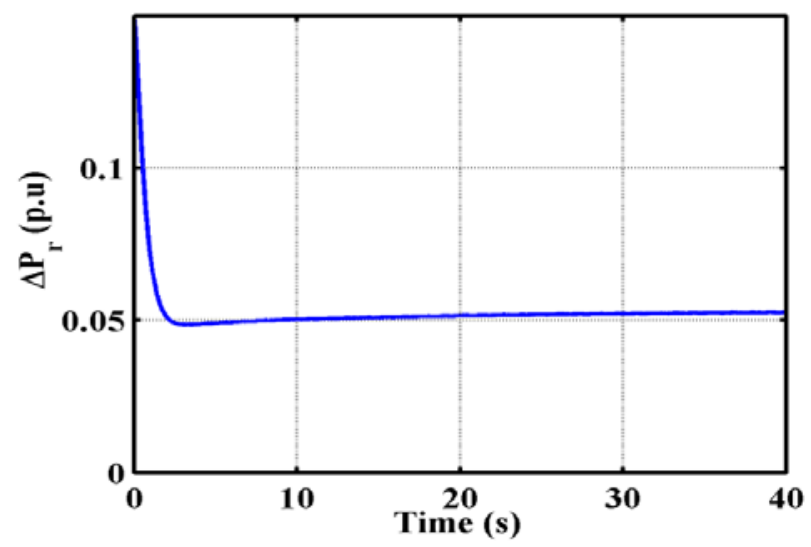

Figure 3(a) Change in reactor normalized thermal power.

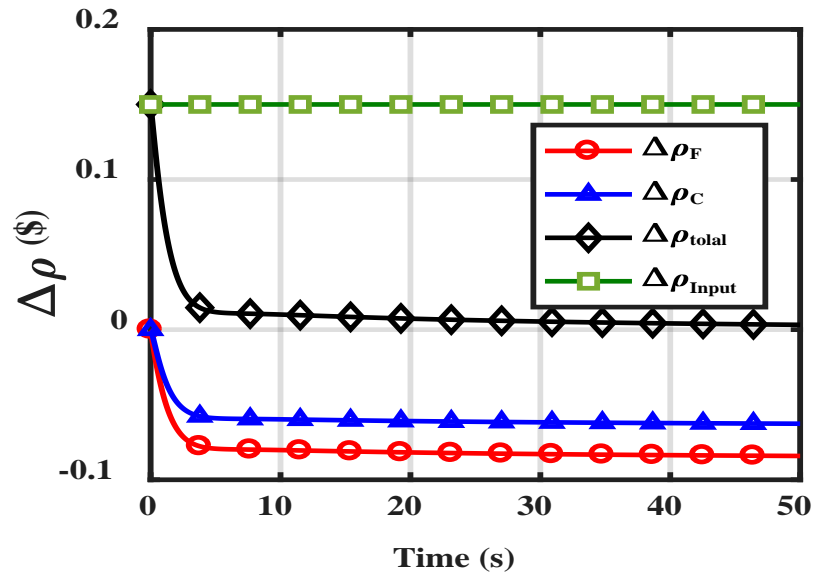

Figure 3(c) Change in core reactivity components. respectively. The rise in fuel temperature produce negative reactivity (Doppler Effect) of (- 0.08405\$) as shown in (Figure 3(c)). Also, the increase in coolant temperature produces negative reactivity feedback of (- 0.06259\$) as shown in (Figure 3(c)) then the total change in core reactivity decreases as shown in (Figure 3(d)). The reactor reaches a new stable operating condition with an increase in power level relative to steady state value of 0.0534 from the normalized reactor power (Figure 3(a)).

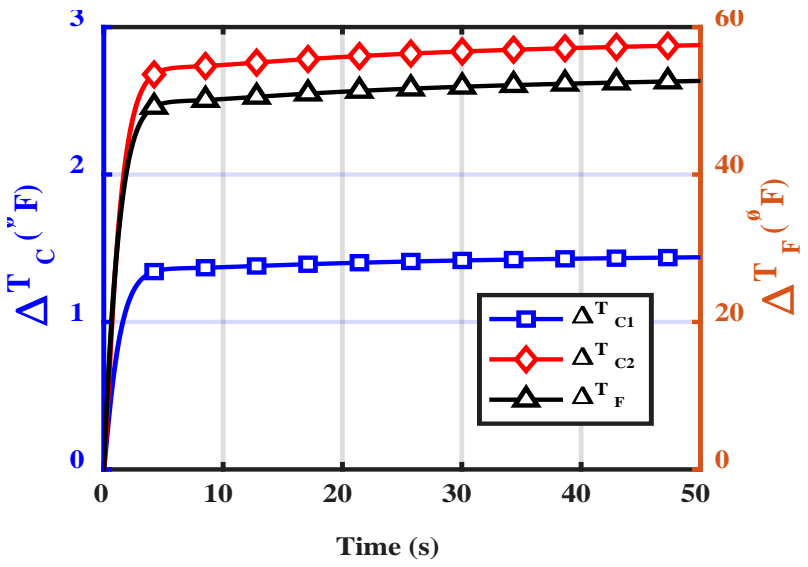

Figure 3(b) Change in fuel and coolant temperature.

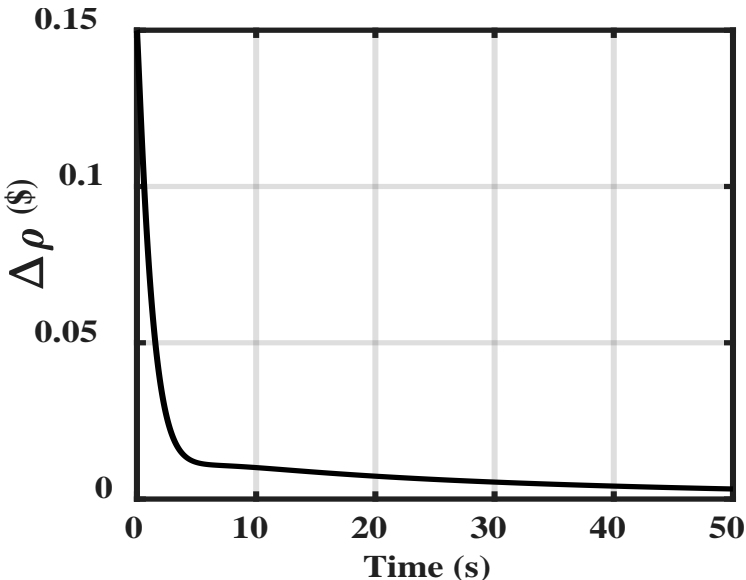

Figure 3(d) Total change in core reactivity.

Figure (3): Reactor variable dynamic response for a step increase in reactivity

\section{B. Dynamics for a Decrease in Inlet Coolant Temperature}

The sudden decrease in coolant inlet temperature case is simulated by assuming sudden $10^{\circ} \mathrm{F}$ step decrease in the core inlet coolant temperature. This is performed to simulate the reactor behavior when the load demand increases and the steam drawn from steam generator increase. Hence, the temperature of primary coolant out from steam generator and inlet to the reactor core decreases. To perform this transient a $10^{\circ} \mathrm{F}$ step 
decrease is applied to the core inlet coolant temperature. This perturbation leads to a decrease in the temperature of the two coolant lumps, e.g. $\Delta \mathrm{T}_{\mathrm{c} 1} \& \Delta \mathrm{T}_{\mathrm{c} 2}$, to a value of $-7.15^{\circ} \mathrm{F}$ and $-4^{\circ} \mathrm{F}$ (Figure 4(b)) respectively. As the coolant temperature decrease it results in positive reactivity in the core (Figure 4(c)). The positive reactivity increases the neutron flux, hence, the reactor power increases rapidly in $6.56 \mathrm{sec}$ by a value of about $11.15 \%$ (i.e. $382.5 \mathrm{MW}$ ) (Figure 4(a)). Correspondingly, as power increases the fuel temperature increases gradually

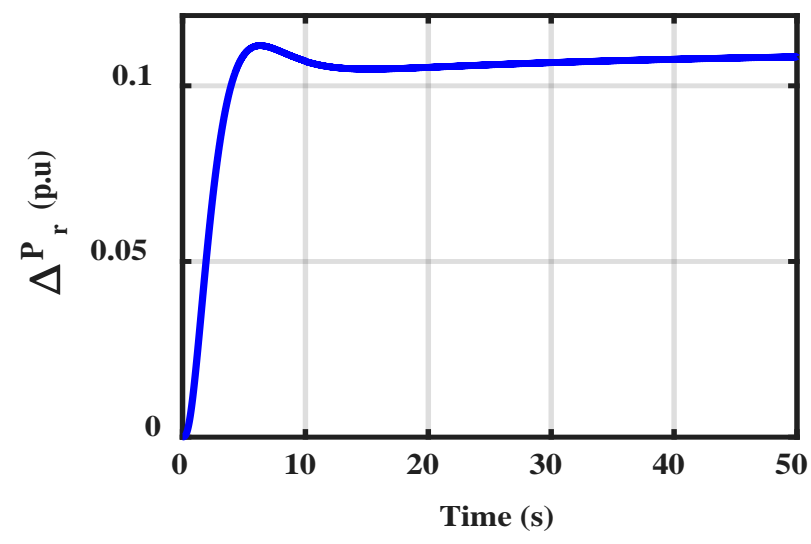

Figure 4(a) Change in reactor normalized thermal power.

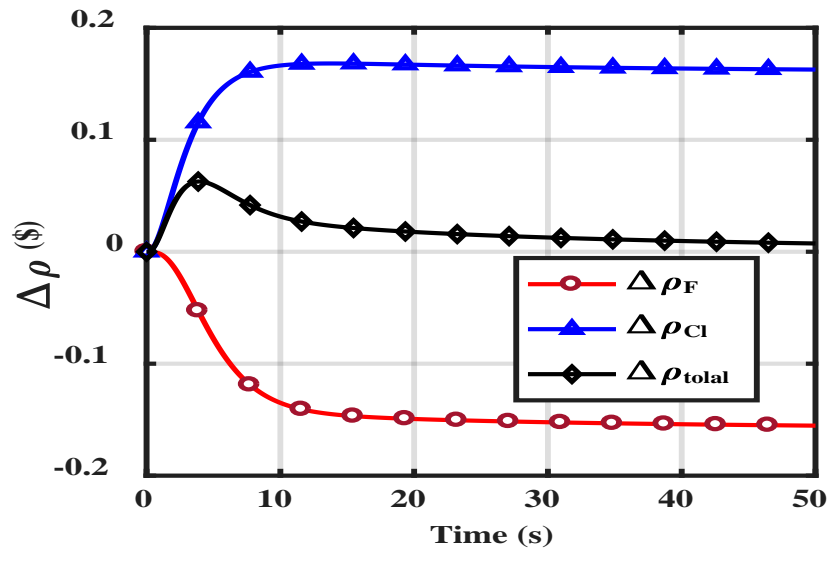

Figure 4(c) Change in core reactivity components. until reaching steady state increase of $100{ }^{\circ} \mathrm{F}$ (Figure 4(b)). Also, the increase in fuel temperature produces negative reactivity in the core which results in a delay time to the coolant positive reactivity at time of $10 \mathrm{sec}$ as in (Figure 4(c)). The positive feedback reactivity from coolant temperature is 0.1663 (\$) and negative reactivity from Doppler Effect is[- 0.1357 (\$)]. The resultant change in core reactivity is shown in (Figure 4(d)). As the change in core reactivity goes to zero the reactor stabilizes at new operating conditions.

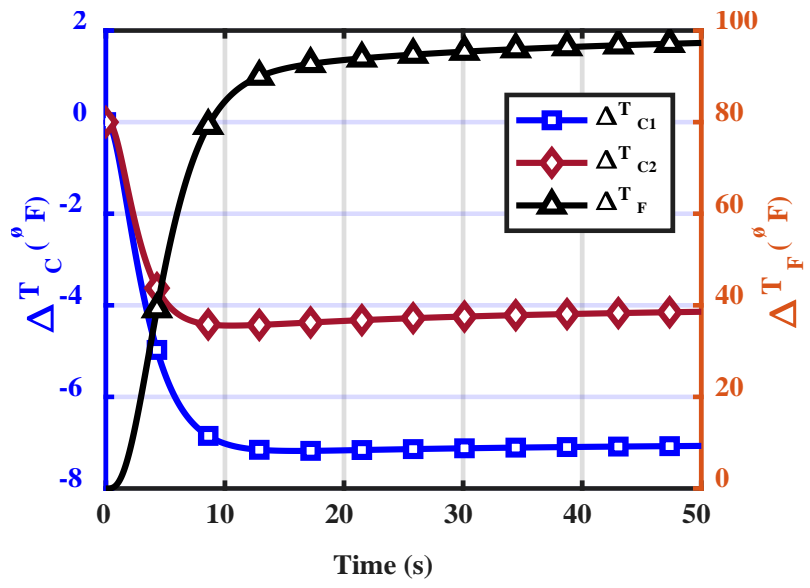

Figure 4(b) Change in fuel and coolant temperature.

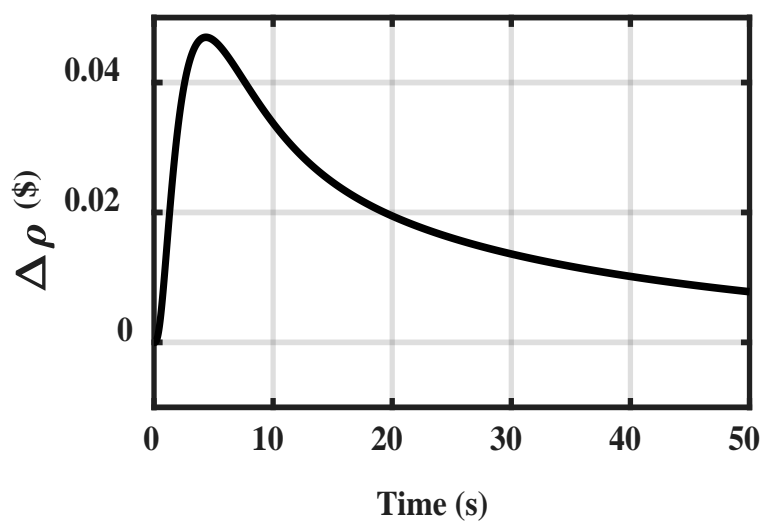

Figure 4(d) Change in core total reactivity.

Figure (4): The dynamic response of reactor parameters for a step decrease to coolant inlet temperature.

\section{Dynamics with decrease in primary coolant flow rate due to grid frequency change.}

A reactor model is developed to simulate the reactor response due to change in grid frequency which results in a change in mechanical rotational speed of reactor coolant pumps and accordingly a reduction in the primary coolant flow rate. In this model, $10 \%$ decrease in the primary cooling reactor cooling water is considered to occur as a result of change in frequency. This decrease results in a sharp 
increase in the temperature of two coolant lumps, e.g. $\Delta \mathrm{T}_{\mathrm{c} 1} \& \Delta \mathrm{T}_{\mathrm{c} 2}$, in the first two seconds as shown in (Figure 5(b)).This sharp increase produces negative reactivity component in core as shown in (Figure 5(c)) and causes a sharp decrease in reactor power (Figure 5(a)) at a 0.69 sec. The reactor power decreases by -0.0755 of rated power and stabilize at -

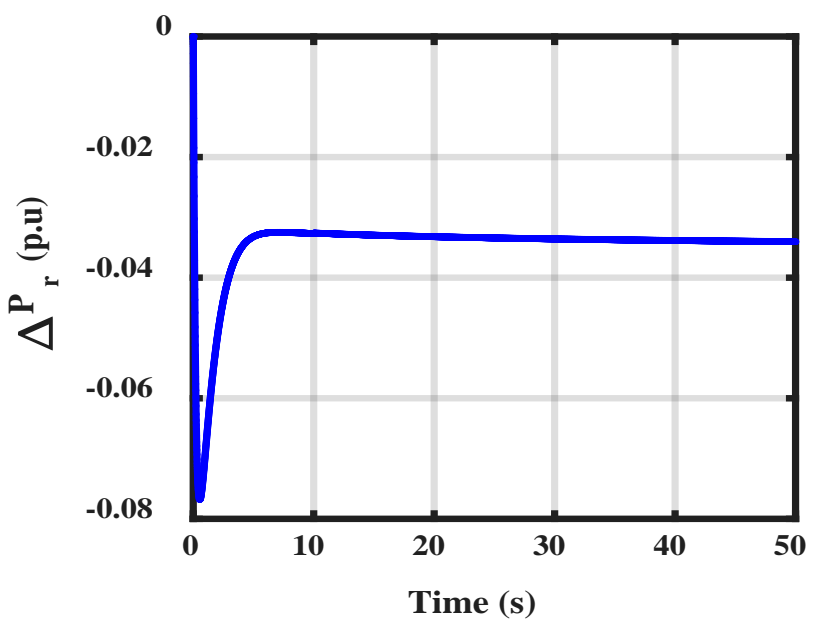

Figure 5(a) Change in reactor normalized thermal power.

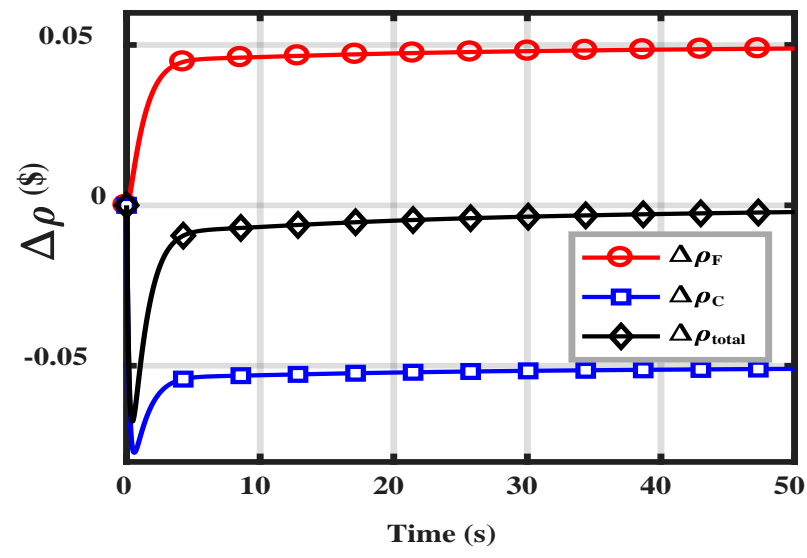

Figure 5(c) Change in core reactivity components.
0.034 of rated power after about $30 \mathrm{sec}$. The fuel temperature follows the power reduction and decreases byabout $30.52{ }^{\circ} \mathrm{F}$ as shown in (Figure 5(b)) and correspondingly, a positive feedback reactivity component is produced in core (Figure 5(c)). The resultant change in core reactivity reaches stable state at $-0.005 \$$ in $50 \mathrm{sec}$, (Figure 5(d)).

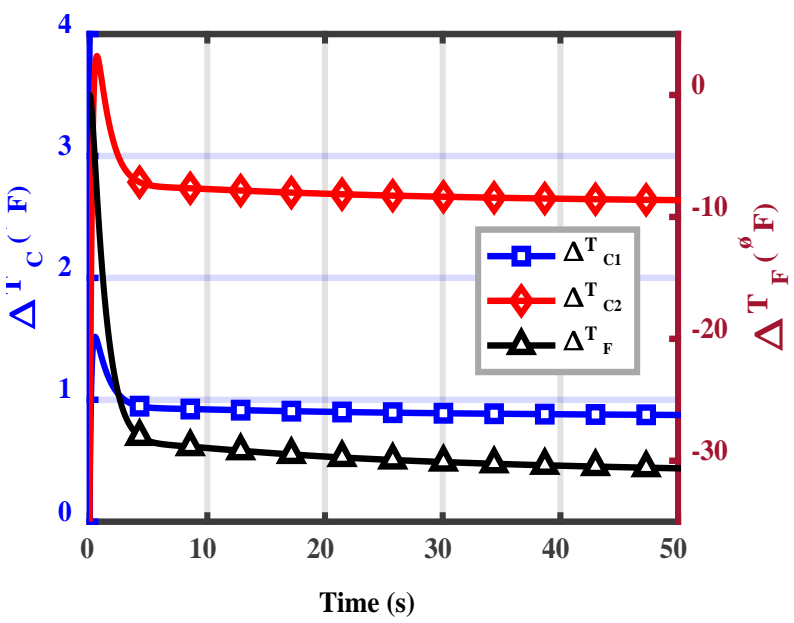

Figure 5(b) Change in fuel and coolant temperature.

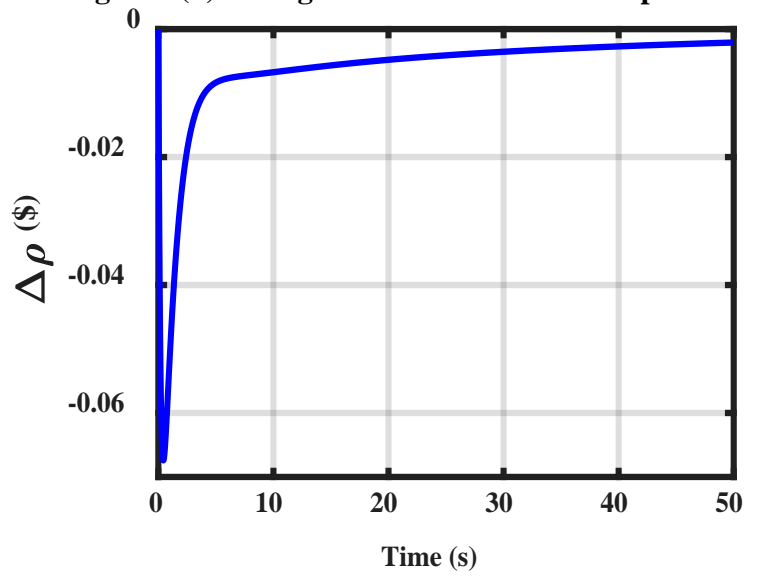

Figure 5(d) Change in core total reactivity.

Figure (5): The dynamic response of reactor parameters for a step decrease in primary coolant flow rate.

\section{Model Validation}

A comparison of reactor core dynamic simulations between the developed model results and previously published results in reference [2] are considered. A case of comparison will be made with reference [2]. Considering the case of positive reactivity insertion, the comparison between normalized power in reference [2] and the presented model is shown in (Figure 6(a)). In both models the transient change in power is the same but for the steady state the value of reference [2] power is higher by about $1.5 \%$ of rated power. This may be attributed to difference in values of feedback reactivity from fuel and coolant temperatures which minimize the power increase. Also a fuel 
temperature comparison is presented in (Figure 6(b)) where, the fuel temperature increases in the first 5 sec to about $50^{\circ} \mathrm{F}$ in both models. While, in the present model the fuel temperature remained in the same range since the change in core power stabilizes

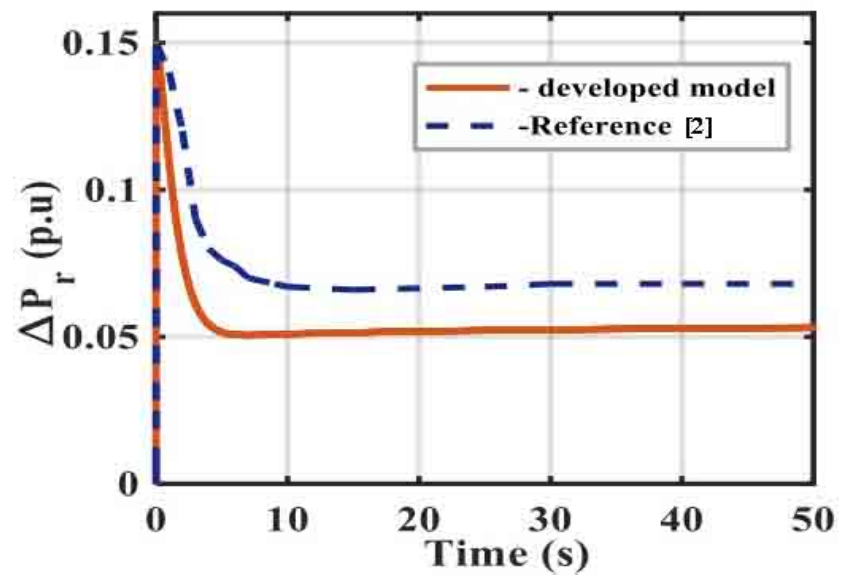

Figure 6(a) Change in normalized reactor thermal power. after 5 sec, (Figure 6(a)). But for reference [2] the fuel temperature decreases about $5^{\circ} \mathrm{F}$ after 5 sec. It should be noted that the differences can be attributed to some differences in design parameter values.

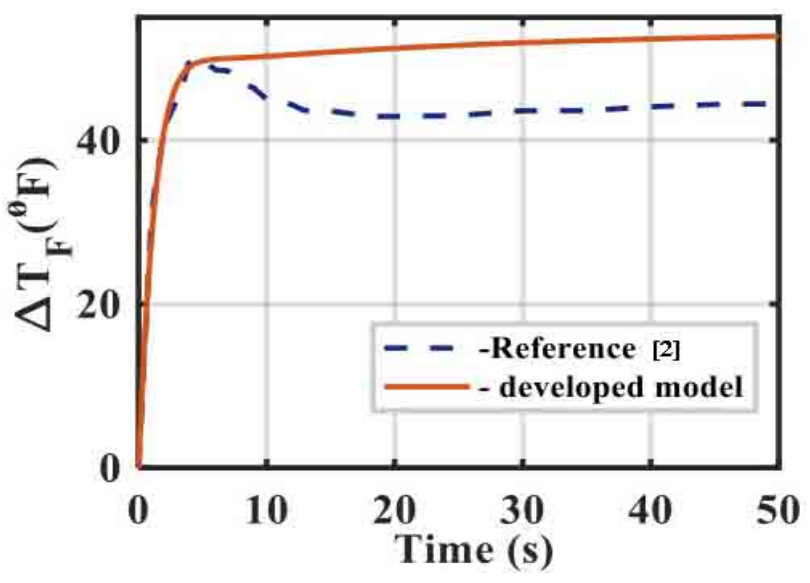

Figure 6(b) Change in fuel temperature.

Figure (6): Comparison between reference simulation and developed model for a change in reactor normalized power and fuel temperature.

\section{Conclusion}

In this work a linearized dynamic model for a PWR nuclear power plant core is developed. The dynamic response of reactor core is studied through transient perturbations introduced to the core inputsparameters. The main points in conclusion are:

- The main role of feedback reactivity from coolant temperature and Doppler Effect is demonstrated as it stabilizes the core power and affects the steady state values.

- The PWR core dynamics is investigated through three different simulated cases of perturbations to reactor model input variables, such as insertion of external reactivity, decrease in primary coolant flow rate and primary coolant inlet temperature.

- The results of the simulated cases are verified by comparison with previously published results which confirm the adequacy of the developed model.

\section{References}

1. Shi, X., Wu, P., Liu, D., Li, X., Zhao, J., Zhang, Y., \& Zhao, Z., (2009) "Modeling and Dynamic Analysis of Nuclear Power Plant Reactor Based on PSASP”, Asia-Pacific Power and Energy Engineering Conference,Proceedings: March 28-31, 2009. IEEE Power \& Energy Society.

2. Tsai CW, Shih C, Wang JR., (2013) "Construction of an elementary model for the dynamic analysis of a pressurized water reactor", Transactions of the Canadian Society for Mechanical Engineering 37(3): 603-610. doi:10.4028/www.scientific.net/AMM.284287.652.

3. Marseguerra, Marzio, Enrico Zio, and Raffaele Canetta. (2004) "Using Genetic Algorithms for Calibrating Simplified Models of Nuclear Reactor Dynamics.” Annals of Nuclear Energy 31(11): 1219-50.

4. Xiong L, Liu D, Wang B, Wu P, Zhao J, Shi X., (2009) "Dynamic Characteristics Analyse of Pressurized Water Reactor Nuclear Power Plant Based on PSASP.” In 4th IEEE Conference on Industrial Electronics and Applications, ICIEA 2009, 3629-34.

5. Zhao, Jie, Ping Wu, and Dichen Liu. (2009) "User-Defined Modeling of Pressurized Water Reactor Nuclear Power Plant Based on PSASP 
and Analysis of Its Characteristics.” In 2009 Asia-Pacific Power and Energy Engineering Conference, IEEE, 1-6. http://ieeexplore.ieee.org/document/4918953/.

6. Gao H, Wang C, Pan W., (2006) "A detailed nuclear power plant model for power system analysis based on PSS/E ”, In 2006 IEEE PES Power Systems Conference and Exposition, PSCE 2006 - Proceedings, , 1582-86. doi:10.1109/PSCE.2006.296149.

7. El-Sefy M., Ezzeldin M., El-Dakhakhni M., Wiebe W., Nagasaki, L. and Mohamed S. (2019) "System Dynamics Simulation of the Thermal Dynamic Processes in Nuclear Power Plants.” Nuclear Engineering and Technology 51(6): 1540-53.

https://doi.org/10.1016/j.net.2019.04.017.

8. S. Arda, and K. Holbert. (2014) "Implementing a Pressurized Water Reactor Nuclear Power Plant Model into Grid Simulations.” IEEE Power and Energy Society General Meeting 2014doi:10.1109/PESGM.2014.6939303

(October).

9. Tiwari, A. P., B. Bandyopadhyay, and G. Govindarajan. (1996) "Spatial Control of a Large Pressurized Heavy Water Reactor.” IEEE Transactions on Nuclear Science 43(4 PART 2): 2440-53.

10. T. W. Kerlin, (1978) "Dynamic Analysis and Control of Pressurized Water Reactors," Control and Dynamic Systems, Advances in Theory and Applications, edited by C.T. Leondes, Academic Press, vol. 14, pp. 103-212, 1978.

11. Puchalski, B., Rutkowski, T. A., and Duzinkiewicz, K., (2017) "Nodal models of Pressurized Water Reactor core for control purposes - A comparison study," Nuclear Engineering and Design, Vol. 322, PP. 444-463. http://dx.doi.org/10.1016/j.nucengdes.2017.07.0 05.

12. Naghedolfeizi, M., (1990) "Dynamic Modeling of a Pressurized Water Reactor Plant for Diagnostics and Control," Master's Thesis, Nuclear Engineering Department, University of Tennessee.

13. "Westinghouse Technology Systems Manual Section 1.2," [Online]. Available:
pbadupws.nrc.gov/docs/ML1122/ML11223A19

5.pdf [Accessed: 12 June. 2019].

\section{APPENDIX A}

\section{Elements of matrix A}

$$
\begin{aligned}
& A_{1,1}=-\beta \mathrm{t} / \Lambda \quad{ }^{A_{1,2}=\lambda_{1} \quad ;}{ }^{A_{1,3}=\lambda_{2}} ;{ }^{A_{1,4}=\lambda_{3}} ; A_{1,5} \\
& =\lambda_{4} ; A_{1,6}=\lambda_{5} ; A_{1,7}=\lambda_{6} ; A_{1,8}=\frac{\alpha_{\mathrm{f}}}{\Lambda} ; A_{1,9}=\frac{\alpha_{\mathrm{c}}}{2 \Lambda} A_{1,10}=\frac{\alpha_{\mathrm{c}}}{\Lambda} ; \\
& A_{2,1=} \beta_{1} /_{\Lambda} ; A_{2,2}=-\lambda_{1} ; A_{3,1} \beta_{2} /_{\Lambda} ; A_{3,3}=-\lambda_{2} ;
\end{aligned}
$$

$A_{4,1}=\beta_{3}{ }_{\Lambda} ; A_{4,4=-\lambda_{3}} ; A_{5,1=} \beta_{4} / \Lambda ; \quad A_{5,5}=-\lambda_{4} ;$

$A_{6,1=} \beta_{5} /_{\Lambda} ; \quad A_{6,6=-\lambda_{5}} ; \quad A_{7,1=} \beta_{6} /_{\Lambda} ; A_{7,7=-\lambda_{6}} ;$

$A_{8,1}=\frac{\mathrm{F}_{\mathrm{r}} \mathrm{P}_{0}}{\left(\mathrm{MC}_{\mathrm{p}}\right)} ; \quad A_{8,8}=\frac{-\mathrm{U}_{\mathrm{fC}} * \mathrm{~A}_{\mathrm{fC}}}{\left(\mathrm{MC}_{\mathrm{p}}\right)_{\mathrm{F}}} ; \quad A_{8,9}=\frac{\mathrm{U}_{\mathrm{fC}} * \mathrm{~A}_{\mathrm{fC}}}{2\left(\mathrm{MC}_{\mathrm{p}}\right)_{\mathrm{F}}} \quad ; \quad A_{8,10}$

$=\frac{\mathrm{U}_{\mathrm{fC}} * \mathrm{~A}_{\mathrm{fC}}}{2\left(\mathrm{MC}_{\mathrm{p}}\right)_{\mathrm{F}}} ; A_{9,1}=\frac{\left(1-\mathrm{F}_{\mathrm{r}}\right) \mathrm{P}_{0}}{\left(\mathrm{MC}_{\mathrm{p}}\right)_{\mathrm{c}}} \quad ; \quad A_{9,8}=\frac{\mathrm{U}_{\mathrm{fC}} * \mathrm{~A}_{\mathrm{fC}}}{\left(\mathrm{MC}_{\mathrm{p}}\right)_{\mathrm{c}}} \quad ; \quad A_{9,9}=-$

$\left[\frac{\mathrm{U}_{\mathrm{fC}} * \mathrm{~A}_{\mathrm{fC}}}{\left(\mathrm{MC}_{\mathrm{p}}\right)_{\mathrm{c}}}+\frac{\mathrm{W}_{\mathrm{PRIM}}}{\mathrm{M}_{\mathrm{C}}}\right] ; A_{9,13}^{A_{9}}=\frac{\mathrm{W}_{\mathrm{PRIM}}}{\mathrm{M}_{\mathrm{C}}} ; A_{10,1}=\frac{\left(1-\mathrm{F}_{\mathrm{r}}\right)_{\mathrm{P}}}{\left(\mathrm{MC}_{\mathrm{p}}\right)_{\mathrm{c}}} ; \quad A_{10,8}$

$=\frac{\mathrm{U}_{\mathrm{fC}} * \mathrm{~A}_{\mathrm{fC}}}{\left(\mathrm{MC}_{\mathrm{p}}\right)_{\mathrm{c}}} \quad ; \quad A_{10,9}=\left[\frac{-\mathrm{U}_{\mathrm{fC}} * \mathrm{~A}_{\mathrm{fC}}}{\left(\mathrm{MC}_{\mathrm{p}}\right)_{\mathrm{c}}}+\frac{\mathrm{W}_{\mathrm{PRIM}}}{\mathrm{M}_{\mathrm{C}}}\right] ; A_{10,10}=-$

$\frac{\mathrm{W}_{\text {PRIM }}}{\mathrm{M}_{\mathrm{C}}} ; A_{11,10}=\frac{\mathrm{W}_{\text {PRIM }}}{\mathrm{M}_{\mathrm{UP}}} ; A_{11,11}=-\frac{\mathrm{W}_{\mathrm{PRIM}}}{\mathrm{M}_{\mathrm{UP}}} ; A_{12,11}=\frac{\mathrm{W}_{\mathrm{PRIM}}}{\mathrm{M}_{\mathrm{HL}}}$

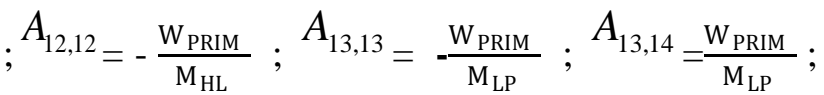

$A_{14,14}=-\frac{\mathrm{W}_{\mathrm{PRIM}}}{\mathrm{M}_{\mathrm{CL}}}$

\section{Element of matrix $B$}

$$
\begin{aligned}
& B_{1,1=1} ; B_{14,2}=\frac{\mathrm{W}_{\mathrm{PRIM}}}{\mathrm{M}_{\mathrm{CL}}} ; B_{9,3}=\left(\frac{\mathrm{T}_{\mathrm{LP} 0}-\mathrm{T}_{\mathrm{C} 10}}{\mathrm{M}_{\mathrm{C}}}\right) ; \\
& B_{10,3}=\left(\frac{\mathrm{T}_{\mathrm{LP} 0}-\Delta \mathrm{T}_{\mathrm{C} 10}}{\mathrm{M}_{\mathrm{C}}}\right) ; B_{11,3}=\frac{\left(\mathrm{T}_{\mathrm{C} 20}-\mathrm{T}_{\mathrm{UP} 0}\right)}{\mathrm{M}_{\mathrm{UP}}} ; B_{12,3} \\
& =\frac{\left(\mathrm{T}_{\mathrm{UP} 0}-\mathrm{T}_{\mathrm{HL} 0}\right)}{\mathrm{M}_{\mathrm{CL}}} ; B_{13,3}=\frac{\left(\mathrm{T}_{\mathrm{CL} 0}-\mathrm{T}_{\mathrm{LP} 0}\right)}{\mathrm{M}_{\mathrm{LP}}} ; B_{14,3} \\
& =\frac{\left(\mathrm{T}_{\mathrm{PSGO} 0}-\mathrm{T}_{\mathrm{CL} 0}\right)}{\mathrm{M}_{\mathrm{CL}}}
\end{aligned}
$$

